\title{
Skeletal muscle metabolism during exercise in patients with chronic heart failure
}

\author{
Maria Schaufelberger, Bengt O Eriksson, Peter Held, Karl Swedberg
}

\begin{abstract}
Objective-To investigate the metabolic response of skeletal muscle to exercise in patients with chronic heart failure and determine its relation to central haemodynamic variables.

Setting-University hospital in Sweden. Participants-16 patients in New York Heart Association class II-III and 10 healthy controls.

Main outcome measures-Skeletal muscle biopsies were obtained from the quadriceps muscle at rest and at submaximal and maximal exercise. Right sided heart catheterisation was performed in eight patients.
\end{abstract}

Results-The patients had lower maximal oxygen consumption than the control group (13.2 (2.9) $v 26.8(4.4) \mathrm{m} / \mathrm{kg} / \mathrm{min}$, $P<0.001)$. They had reduced activities of citrate synthetase $(P<0.05)$ and 3 -hydroxyacyl-CoA dehydrogenase $(P<0.05)$ compared with the controls. At maximal exercise adenosine triphosphate $(P<0.05)$, creatine phosphate $(P<0.01)$, and glycogen $(P<0.01)$ were higher whereas glucose $(P<0.001)$ and lactate $(P<0.06)$ were lower in the patients than in the controls. Citrate synthetase correlated inversely with skeletal muscle lactate at submaximal exercise $(r=-0.90$, $P<0.003)$. No correlations between haemodynamic variables and skeletal muscle glycogen, glycolytic intermediates, and adenosine nucleotides during exercise were found.

Conclusion-Neither skeletal muscle energy compounds nor lactate accumulation were limiting factors for exercise capacity in patients with chronic heart failure. The decreased activity of oxidative enzymes may have contributed to the earlier onset of anaerobic metabolism, but haemodynamic variables seemed to be of lesser importance for skeletal muscle metabolism during exercise.

(Heart 1996;76:29-34)

Keywords: heart failure, exercise, metabolism, skeletal muscle

Patients with chronic heart failure have a limited exercise capacity because of dyspnoea and/or fatigue. The correlation between central haemodynamic variables at rest and exercise performance is poor. ${ }^{1-3}$ Changed skeletal muscle metabolism may contribute to the limited exercise capacity. Investigations with ${ }^{31} \mathrm{P}$ nuclear magnetic resonance spectroscopy have shown that phosphocreatine is depleted faster and $\mathrm{pH}$ falls earlier in skeletal muscles in patients with chronic heart failure than in healthy controls during exercise. ${ }^{4-6}$ In biopsies from the lateral vastus muscle Sullivan and coworkers ${ }^{7}$ found less phosphocreatine depletion and lactate accumulation at maximal exercise in patients with chronic heart failure than in controls. This finding was not confirmed by Näveri et al. ${ }^{8}$

The increase in adrenaline during exercise contributes to the increased glycolysis in healthy people. ${ }^{9}$ Patients with chronic heart failure have an increased activation of the neurohumoral system, ${ }^{10}$ which might influence glycolysis during exercise.

Patients operated upon for coarctation of the aorta have an increased gradient between lactate in the quadriceps muscle and blood. ${ }^{11}$ Sullivan et al did not find such a gradient in patients with chronic heart failure. ${ }^{7}$

The objective of the present study was to see whether there is any difference in the metabolic response of skeletal muscle to exercise in patients with chronic heart failure and in healthy controls. Another objective was to find out if there is a relation between central haemodynamic variables, neurohormones, oxidative enzymes, and glucose metabolism in skeletal muscle during exercise. We also wanted to examine if there is a blood/muscle lactate gradient in patients with chronic heart failure.

\section{Patients and methods}

PATIENTS

Sixteen patients (13 men) with chronic heart failure (New York Heart Association class IIIII) were studied (table 1). All had an ejection fraction of $\leqslant 40 \%$ (range 15-40) and had had heart failure for at least six months (range 6-134). Patients with diabetes mellitus, intermittent claudication, angina pectoris, pulmonary disease, and other conditions limiting physical performance were excluded. Ten age matched healthy individuals were used as a control group (table 1).

All subjects underwent maximal exercise testing with respiratory gas analysis. A muscle biopsy was taken from the lateral vastus muscle at rest, at anaerobic threshold, and at maximal work. Blood samples from the femoral vein and finger tip were drawn at corresponding times. The protocol was approved by the ethi- 
Table 1 Patient characteristics (mean (SD))

\begin{tabular}{|c|c|c|c|}
\hline Characteristic & Patients $(n=16)$ & Controls $(n=10)$ & Pvalue \\
\hline Age $(y r)^{\star}$ & $64 \cdot 6(10 \cdot 5)$ & $68.0(3.0)$ & NS \\
\hline Sex (male/female) & $13 / 3$ & $9 / 1$ & NS \\
\hline Weight $(\mathrm{kg})^{\star}$ & $80 \cdot 0(15 \cdot 2)$ & $75 \cdot 6(11 \cdot 8)$ & NS \\
\hline \multicolumn{4}{|l|}{ Diagnosis: } \\
\hline Coronary artery disease & 11 & - & - \\
\hline Dilated cardiomyopathy & 4 & - & - \\
\hline Hypertension & 1 & - & - \\
\hline Duration of heart failure (mnth) ${ }^{\star}$ & $51 \cdot 8(43 \cdot 6)$ & - & - \\
\hline \multicolumn{4}{|l|}{ NYHA Class: } \\
\hline II & 6 & - & - \\
\hline III & 10 & - & - \\
\hline Ejection fraction $(\%)^{\star}$ & $27 \cdot 9(7 \cdot 4)$ & - & - \\
\hline Frusemide dose $(\mathrm{mg})^{\star}$ & $100(58)$ & - & - \\
\hline BBlockers & 6 & - & - \\
\hline Vasodilators & 5 & - & - \\
\hline ACE inhibitors & 10 & - & - \\
\hline Digitalis & 13 & - & - \\
\hline
\end{tabular}

NYHA, New York Heart Association; ACE, angiotensin converting enzyme.

cal committee of Göteborg University, and written informed consent was obtained for each subject.

\section{STUDY PROTOCOL}

Three exercise tests were performed with patients and controls in the upright position on a bicycle ergometer. We used a ramp protocol with a $10 \mathrm{~W}$ increase every minute until exhaustion. The first exercise test familiarised the subjects with the method and the anaerobic threshold was determined. The Borg scale was used to evaluate fatigue and dyspnoea. ${ }^{12}$ The oxygen and carbon dioxide content in expired air was measured on line (Medical Graphics 2001 System minute ventilation, St Paul, Minnesota, USA). $\mathrm{VO}_{2}$ max was defined as the $\dot{\mathrm{VO}}_{2}$ reached when $\dot{\mathrm{VO}}_{2}$ increased by $<1$ $\mathrm{ml} / \mathrm{kg} / \mathrm{min}$ with an increase in workload. Where no plateau was found $\dot{V}_{2}$ max was defined as the average $\dot{\mathrm{VO}}_{2}$ value during the last 30 seconds. Ventilatory anaerobic threshold was evaluated independently by three observers. Anaerobic threshold was defined according to Wasserman et al and Simonton et al and expressed in $\mathrm{ml} / \mathrm{kg} / \mathrm{min} .{ }^{13}{ }^{14}$ Before the second exercise test a femoral venous catheter was introduced and placed $10 \mathrm{~cm}$ antegradely. Blood samples from the femoral vein and finger tip were taken at the same time as the muscle biopsies. Samples were taken at rest, during a short interruption of exercise at anaerobic threshold, and immediately after peak exercise. In two patients no anaerobic threshold was found. In these subjects the second sample was taken at $65 \%$ of maximal exercise time. Lactate content was analysed in blood from the femoral vein and finger capil-
Table 3 Skeletal muscle enzyme activity (mean (SD)) in patients and controls

\begin{tabular}{|c|c|c|}
\hline Enzyme & Patients & Controls \\
\hline \multirow{5}{*}{$\begin{array}{l}\text { Lactate dehydrogenase } \\
\text { Phosphorylase } \\
\text { Citrate synthetase } \\
\text { 3-hydroxyacyl-CoA- } \\
\text { dehydrogenase }\end{array}$} & $174(81) \dagger$ & $120(43)$ \\
\hline & $3 \cdot 2(1 \cdot 3)$ & $3.8(1.6)$ \\
\hline & $3.9(0.8)^{\star}$ & $4.9(1.5)$ \\
\hline & $3(1,0) \star$ & $5.4(1.6)$ \\
\hline & $4 \cdot 3(1 \cdot 0)^{n}$ & $3.4(1.0)$ \\
\hline
\end{tabular}

laries and measured by the method by Lowry and Passonneau. ${ }^{15}$

The right heart was catheterised through the internal jugular vein in eight patients within one week of muscle biopsy. Heart rate and rhythm were monitored continuously. Right atrial, pulmonary artery, and pulmonary capillary wedge pressures were measured with the Swan-Ganz catheter. Cardiac output (where possible, a mean of three estimates) was measured by the thermodilution technique. The first measurement was made with the subject supine 15 minutes after insertion of the catheter. New measurements were made with the patient sitting on the bicycle, during exercise at anaerobic threshold, and at maximal exercise.

In seven patients venous blood was drawn after 30 minutes rest for analysis of aldosterone, angiotensin II, noradrenaline, and adrenaline. Aldosterone was determined by radioimmunoassay according to the procedure described by Walsh et al ${ }^{16}$ using kits from Diagnostic Products (Los Angeles, California). Angiotensin II in EDTA plasma was measured by radioimmunoassay as described by Nussberger $e t a l^{17}$ with kits from Buehlman laboratories (Basel, Switzerland). Noradrenaline and adrenaline were determined in EDTA plasma by a radioenzymatic method $^{18}$ using kits from Amersham (UK)

\section{SKELETAL MUSCLE BIOPSY}

Percutaneous biopsies were taken under local anaesthesia with a conchotome from the middle part of the lateral vastus muscle. The samples were immediately frozen in liquid nitrogen and stored at $-70^{\circ} \mathrm{C}$. The biopsy samples were weighed and fluorometrically analysed for adenosine triphosphate, creatine phosphate, glycogen, glucose, glucose-6-phosphate, and lactate according to the modified Lowry et al methods as described by Karlsson. ${ }^{19}$ All values are expressed in

Table 2 Exercise variables and blood lactate concentrations in patients and controls at rest, anaerobic threshold, and maximal exercise (mean (SD))

\begin{tabular}{|c|c|c|c|c|c|c|}
\hline & \multicolumn{2}{|l|}{ Rest } & \multicolumn{2}{|c|}{ Anaerobic threshold } & \multicolumn{2}{|l|}{ Maximal exercise } \\
\hline & Patients & Controls & Patients & Controls & Patients & Controls \\
\hline Heart rate (beats/min) & $76(18)$ & $69(17)$ & 109 (17) & $108(16)$ & $127(18) \ddagger$ & $162(14)$ \\
\hline Systolic arterial pressure $(\mathrm{mm} \mathrm{Hg})$ & $124(15) \ddagger$ & $148(14)$ & $140(18)^{\star}$ & $170(55)$ & $153(19) \dagger$ & $207(15)$ \\
\hline Workload (W) & 0 & 0 & $49 \cdot 2(18 \cdot 5) \ddagger$ & $93.2(25.8)$ & $93.2(21 \cdot 9) \ddagger$ & $190 \cdot 3(40 \cdot 7)$ \\
\hline $\mathrm{Vo}(\mathrm{ml} / \mathrm{kg} / \mathrm{min})$ & $4 \cdot 6(1 \cdot 2)^{\star}$ & $6 \cdot 0(1 \cdot 1)$ & $10 \cdot 1(2 \cdot 2) \ddagger$ & $16 \cdot 5(2 \cdot 4)$ & $13 \cdot 2(2 \cdot 9) \neq$ & $25 \cdot 6(4 \cdot 3)$ \\
\hline Respiratory quotient & $0.76(0.08)$ & $0.73(0.07)$ & $0.96(0.09)$ & $0.95(0.04)$ & $1 \cdot 17(0 \cdot 10)$ & $1.21(0.08)$ \\
\hline Capillary lactate $(\mathrm{mmol} / \mathrm{l})$ & $2 \cdot 2(0 \cdot 9)$ & $\begin{array}{l}1 \cdot 7(0 \cdot 4) \\
(\mathrm{n}=9)\end{array}$ & $\begin{array}{l}3 \cdot 1(1 \cdot 4) \\
(\mathrm{n}=15)\end{array}$ & $\begin{array}{l}2 \cdot 8(0 \cdot 9) \\
(\mathrm{n}=9)\end{array}$ & $4 \cdot 7(1 \cdot 3)^{\star}$ & $\begin{array}{l}6 \cdot 2(1 \cdot 5) \\
(n=9)\end{array}$ \\
\hline Femoral vein lactate $(\mathrm{mmol} / \mathrm{l})$ & $1 \cdot 6(0 \cdot 4)$ & $\begin{array}{l}1 \cdot 6(0 \cdot 4) \\
(n=9)\end{array}$ & $\begin{array}{l}3 \cdot 6(1 \cdot 4) \\
(n=15)\end{array}$ & $\begin{array}{l}3 \cdot 6(1 \cdot 1) \\
(n=9)\end{array}$ & $\begin{array}{l}7.9(3.3) \\
(\mathrm{n}=14)\end{array}$ & $\begin{array}{l}8 \cdot 4(2 \cdot 4) \\
(n=8)\end{array}$ \\
\hline
\end{tabular}

$\star \mathrm{P}<0.05,+\mathrm{P}<0.01, \neq \mathrm{P}<0.001$ patients $v$ controls 
Table 4 Skeletal muscle glucose metabolism in patients and controls at rest and during exercise

\begin{tabular}{|c|c|c|c|c|c|c|}
\hline & \multicolumn{2}{|l|}{ Rest } & \multicolumn{2}{|c|}{ Anaerobic threshold } & \multicolumn{2}{|c|}{ Maximal exercise } \\
\hline & Patients & Controls & Patients & Controls & Patients & Controls \\
\hline Adenosine triphosphate & $3.6(0.9)$ & $3 \cdot 3(1 \cdot 0)$ & $3.9(0.8) \dagger$ & $2 \cdot 8(0 \cdot 6)$ & $3 \cdot 3(1 \cdot 0) \S$ & $2.5(0.8)$ \\
\hline Creatine phosphate & $12 \cdot 8(5 \cdot 2)$ & $13 \cdot 3(4 \cdot 8)$ & $13 \cdot 8(3 \cdot 7) \ddagger$ & $8 \cdot 1(2 \cdot 1)$ & $11 \cdot 0(5 \cdot 0) \ddagger$ & $5 \cdot 5(2 \cdot 7)$ \\
\hline Lactate & $2.9(1.7)^{\star}$ & $1 \cdot 7(0 \cdot 8)$ & $3.8(1.4)$ & $4 \cdot 7(3 \cdot 2)$ & $5 \cdot 4(3 \cdot 4)^{\star}$ & $11 \cdot 2(9 \cdot 6)$ \\
\hline Glucose-6-phosphate & $0 \cdot 5(0.3)$ & $0.4(0.2)$ & $0 \cdot 4(0 \cdot 2)$ & $0.4(0.2)$ & $0 \cdot 5(0 \cdot 3)$ & $0.6(0.4)$ \\
\hline Glucose & $1.7(0.7)^{\star}$ & $2 \cdot 4(1 \cdot 2)$ & $1.8(0.6) \dagger$ & $3 \cdot 3(1 \cdot 3)$ & $2 \cdot 1(0 \cdot 8) \|$ & $3.4(0.8)$ \\
\hline Glycogen & $77(18)$ & $88(26)$ & $75(19)$ & $67(15)$ & $70(18) \ddagger$ & $44(20)$ \\
\hline
\end{tabular}

All data are mean (SD) expressed in mmol $/ \mathrm{kg} \mathrm{ww} .{ }^{\star} \mathrm{P} \leqslant 0.06,+\mathrm{P} \leqslant 0.02, \ddagger \mathrm{P} \leqslant 0.01, \S \mathrm{P}<0.05, \| \mathrm{P}<0.001$ patients $v$ controls.

$\mathrm{mmol} / \mathrm{kg}$ ww. A second biopsy sample was weighed and the glycolytic enzymes, phosphorylase and lactate dehydrogenase, and the oxidative enzymes, citrate synthetase and 3-hydroxyacyl-CoA dehydrogenase, were analysed fluorometrically. ${ }^{20-23}$ The enzyme activities are expressed in $\mu \mathrm{mol} / \mathrm{g} \mathrm{ww} / \mathrm{min}$.

STATISTICAL ANALYSIS

Data are expressed as mean (SD). An unpaired, two tailed Student's $t$ test was used
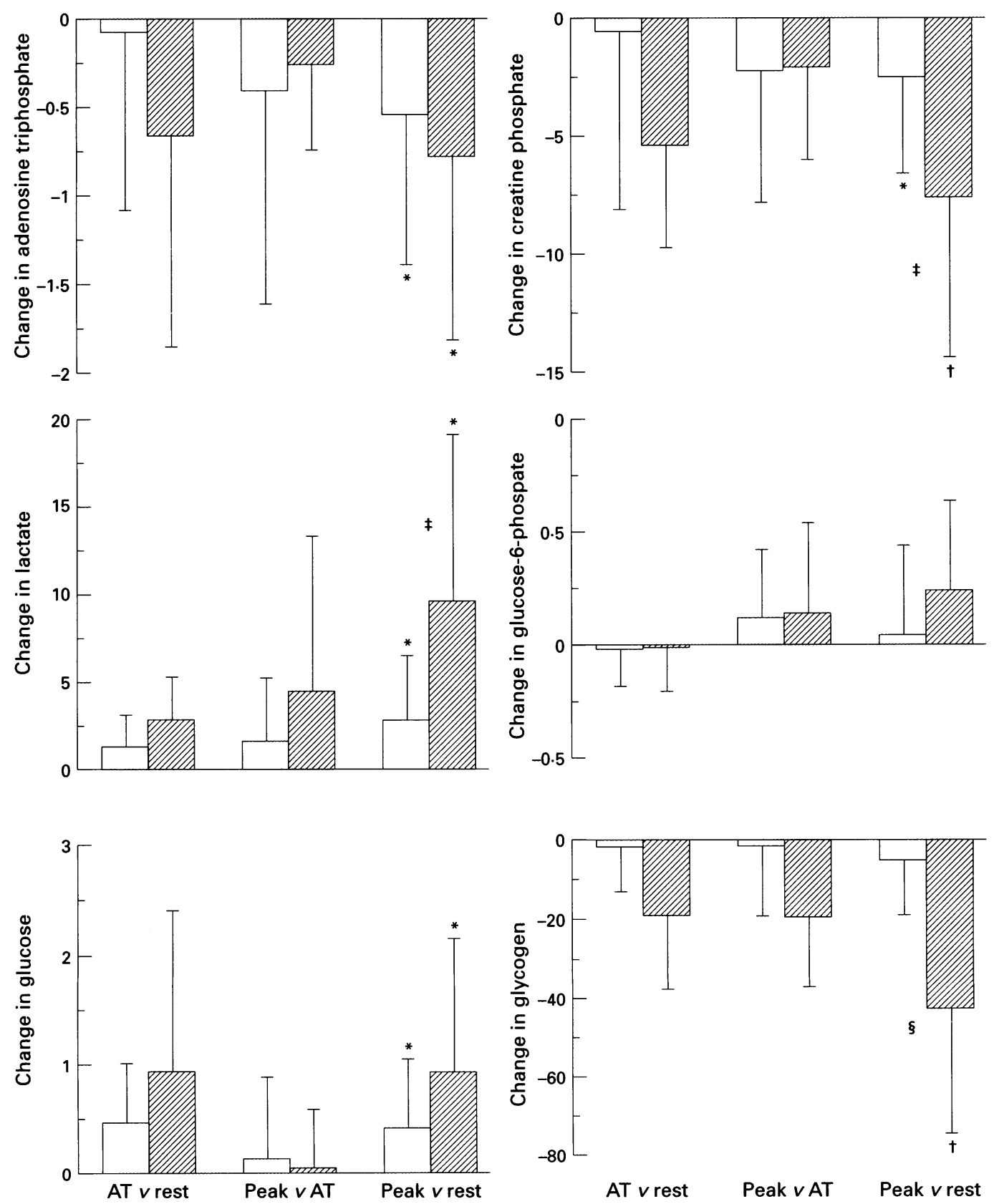

AT $v$ rest

Peak $v$ AT

Peak $v$ rest
1 Changes in All values are in mmollkg ww. ${ }^{\star} P<0.05,+P<0.01$ threshold. Open bars, patients; hatched bars, controls.
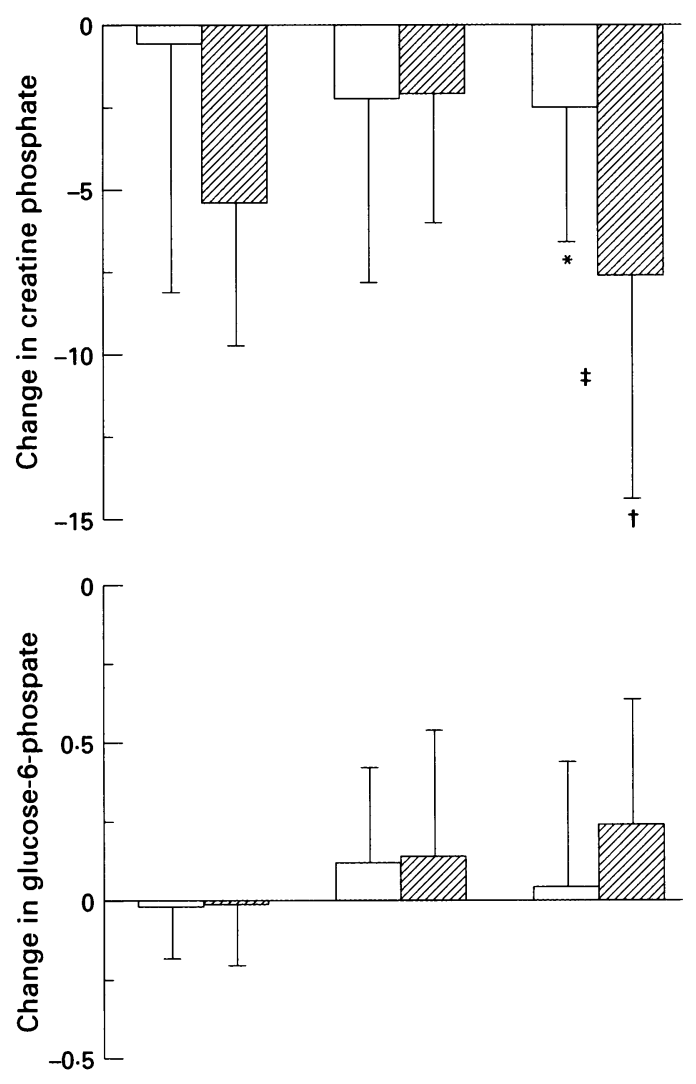

for between group comparisons. For intracomparisons a paired, two tailed between variables were examined by simple and multiple regression by using the Statview II statistical program, MacIntosh (version

Results

All patients and controls stopped exercise

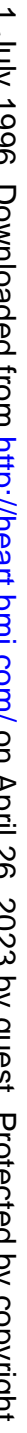


because of dyspnoea or fatigue, reaching level $17-19$ on the Borg scale where 20 is maximum. Workload and $\dot{\mathrm{VO}}_{2}$ at anaerobic threshold and maximal exercise were significantly lower in the patient group than in the control group (table 2). Maximal heart rate was also lower in the patients than in the controls but the respiratory quotient at peak exercise did not differ between the groups (table 2).

In eight patients and three controls biopsies could not be obtained at submaximal work. No representative biopsies were obtained in three patients at maximal work.

The activity of the oxidative enzymes citrate synthetase and 3-hydroxyacyl-CoA dehydrogenase was significantly lower in the patients than in the controls (table 3 ). There was a tendency towards higher activity of lactate dehydrogenase in the patients than in the controls (table 3).

At rest patients had higher lactate concentrations in skeletal muscle than the controls. At submaximal and maximal exercise adenosine triphosphate and creatine phosphate were significantly higher in the patients than in the controls (table 4). Glucose was significantly higher in the controls than in the patients at all points measured. Glycogen were higher in the patients than in the controls whereas the lactate concentrations in skeletal muscle were higher in the controls than in the patients at maximal exercise (table 4). There were no significant differences in the changes in adenosine triphosphate, glucose-6-phosphate, and glucose (fig 1). The increase in skeletal muscle lactate was significantly smaller in the patients than in the controls (fig 1). Decreases in creatine phosphate and glycogen were smaller in the patients than in the controls (fig 1). At the same workload (patients' maximal workload $v$ controls' submaximal workload) there was no significant difference in glycolytic intermediates, glycogen, and adenosine nucleotides between patients and controls.

Capillary blood lactate was lower at peak exercise in the patients than in the controls whereas femoral vein lactate did not differ between the groups (table 2). Capillary blood lactate and femoral vein lactate were higher in the patients than in the controls at the same workload $(P<0.001$ and $P<0.01)$. No differences in the lactate gradient between skeletal

Figure 2 Relation between citrate synthetase and skeletal muscle lactate at anaerobic threshold in patients with chronic heart failure. muscle, capillary blood, or femoral venous blood was found between the groups.

The citrate synthetase activity in the patients was inversely correlated with skeletal muscle lactate at anaerobic threshold (fig 2). 3-Hydroxyacyl-CoA dehydrogenase showed the same trend but it did not reach statistical significance. No correlation was found between the oxidative enzymes and skeletal muscle lactate at maximal exercise.

Angiotensin II and aldosterone were correlated with skeletal muscle lactate at peak exercise $(r=0.86 ; \mathrm{P}<0.03, \mathrm{n}=6$ and $r=0.89$; $\mathrm{P}<0.02, \mathrm{n}=6)$. A correlation was also found between skeletal muscle lactate at maximal exercise and cardiac index at rest $(r=$ 0.96; $P<0.003, n=6$ ). Multiple regression analysis showed that only cardiac index at rest correlated significantly with skeletal muscle lactate at maximal exercise $(P<0.05)$. No correlations were found between haemodynamic variables and skeletal muscle glycogen, glycolytic intermediates, and adenosine nucleotides during exercise.

\section{Discussion}

Patients with chronic heart failure are limited in their exercise performance by dyspnoea, fatigue, or both. Administration of positive inotropic agents does not always increase exercise performance although cardiac output increases. $^{2425} \mathrm{~A}$ change in skeletal muscle metabolism has been seen in patients with chronic heart failure. ${ }^{2627} \mathrm{We}$ investigated whether the limited exercise performance in patients with chronic heart failure was the result of a change in skeletal muscle metabolism. We found higher concentrations of creatine phosphate, adenosine triphosphate, and glycogen in these patients compared with controls at peak exercise. Skeletal muscle lactate was higher at rest but tended to be lower at peak exercise in the patients than in the controls. The decreases in creatine phosphate and glycogen were significantly less in the patients than in the controls whereas the increase in skeletal muscle lactate was significantly lower in the patients than in the controls. When skeletal muscle metabolism at the same workload (patients' maximal $v$ controls' submaximal) was compared there was no difference between the groups. We could not find any blood/muscle lactate gradient in our patients in contrast to the observations reported by Eriksson and Hanson in patients operated upon for coarctation of the aorta. ${ }^{11}$

In both groups exercise performance was continued to exhaustion and was evaluated by the Borg scale. The lower skeletal muscle lactate concentrations and reduced depletion of phosphocreatine at maximal exercise in patients with chronic heart failure compared with controls accords with the results of Sullivan et $a l^{7}$ but not with ${ }^{31} \mathrm{P}$ nuclear magnetic resonance studies. ${ }^{56}$ The contrasting results may be due to the different kind of exercise performed in the different investigations. In the ${ }^{31} \mathrm{P}$ nuclear magnetic resonance studies only small muscle groups were tested 
at a maximal effort whereas in our study and in the investigation by Sullivan et al symptom limited bicycle exercise tests were performed. Thus different factors might limit exercise performance in the different tests.

During chronic hypobaric hypoxia healthy people had lower maximal exercise performance, despite the same degree of fatigue, less phosphocreatine depletion, and lower lactate concentrations at peak exercise than before exposure to hypoxia. ${ }^{28}$ When blood flow to exercising limbs in healthy subjects is reduced by external pressure, the blood lactate concentrations increase faster but reach a lower maximum value ${ }^{29}$; this accords with our results in patients with chronic heart failure. These similarities indicate that hypoxia and diminished blood flow may play a part in the changed skeletal muscle metabolism seen in chronic heart failure. Lactate concentrations may be of less importance for leg fatigue in this condition, as suggested by the observation of Wilson et al that dichloroacetate, which reduces lactate formation, did not influence exercise performance in chronic heart failure. ${ }^{30}$ Other factors which might influence fatigue, such as neuromuscular junction transmission and central motor drive, do not seem to be altered in patients with chronic heart failure. ${ }^{31}$

Patients with chronic heart failure have a decreased skeletal muscle mass. ${ }^{32}$ If a smaller muscle mass must perform the same work as a large muscle mass, it is possible that the smaller muscle mass is more easily fatigued. An increased percentage of type II B fibres and a decreased percentage of type I fibres have been reported in patients with chronic heart failure. ${ }^{27} 3334$ This change in fibre type composition might contribute to the earlier fatigue seen in chronic heart failure. The type II $\mathrm{B}$ muscle fibres preferentially release lactate, which is used by the type I fibres, but a simultaneous release and uptake of lactate has also been noticed in the type II B muscle fibres. ${ }^{35}$ The increased percentage of type II $B$ fibres and decreased percentage of type I fibres seen in patients with chronic heart failure $^{273334}$ might influence lactate turnover.

Adenosine triphosphate concentrations were higher in patients than in controls at maximal exercise. Sullivan et $a l^{7}$ reported a similar trend. In our patients glycogen and phosphocreatine were less depleted than in the controls. This is most probably because the total work performed by the patients was lower than in the controls. Sullivan et $\mathrm{al}^{7} \mathrm{did}$ not find any difference in glycogen concentrations at maximal exercise. The difference between their results and ours might be due to the fact that their patients tended to have lower glycogen concentrations at rest than the control group.

The lack of correlation between central haemodynamic variables at peak exercise and glycogen, glycolytic intermediates, and adenosine nucleotides during exercise suggests that haemodynamic variables during exercise are less important to skeletal muscle metabolism at maximal exercise. However, not many patients were investigated to determine cen- tral haemodynamic variables.

Like others we found that patients with chronic heart failure had lower oxidative enzyme activity than controls. ${ }^{27} 34$ This may, in part, be due to deconditioning and is partially reversible after training. ${ }^{36}$ The inverse relation between skeletal muscle lactate at anaerobic threshold and the oxidative enzymes suggests that decreased activity of oxidative enzymes could influence the earlier onset of anaerobic metabolism seen in patients with chronic heart failure. These results accord with the findings of Sullivan et al. ${ }^{7}$ The lack of correlation between skeletal muscle lactate during maximal exercise and oxidative enzymes suggests that decreased oxidative enzyme activity is not the limiting factor for skeletal muscle metabolism at peak exercise in patients with chronic heart failure.

The reason for the limited exercise capacity in patients with chronic heart failure is not yet fully understood, but neither lack of substrate in skeletal muscle nor oxidative enzyme capacity seem to be the limiting factor. Diminished blood flow and decreased skeletal muscle mass are most probably important ${ }^{32} 37$ as is cardiac functional reserve. ${ }^{32}$

\section{LIMITATIONS OF THE STUDY}

Experimental studies have shown diverging effects of the influence of $\beta$ blockers on skeletal muscle metabolism, ${ }^{37} 38$ and one objection to this study may be that six of our patients were taking $\beta$ blockers. Maximal heart rate was significantly lower in the $\beta$ blocker treated group (113 with and 135 without $\beta$ blockers, $P<0.03$ ), but no significant differences between the patients treated with and without $\beta$ blockers were seen in skeletal muscle metabolism, $\dot{\mathrm{V}}_{2}$ max, and peak workload. Another limitation of the study is that a biopsy at submaximal exercise was not obtained in all subjects. Another objection may be that the metabolic results are expressed in $\mathrm{mmol} / \mathrm{kg}$ ww. Broqvist et al found increased water content in skeletal muscle in 22 patients with oedema. ${ }^{40}$ On the other hand Dyckner and Wester did not see any significant change of skeletal muscle water content in 297 patients with heart failure. ${ }^{41}$ None of our patients had oedema, which makes it reasonable to believe that the metabolic results where not influenced by increased skeletal muscle water content.

\section{CONCLUSION}

Patients with chronic heart failure have less depletion of glycogen and phosphocreatine and a lower increase of lactate in skeletal muscle during exercise than controls. Neither substrate content nor skeletal muscle lactate concentrations are limiting factors for exercise performance in patients with chronic heart failure. We thank Anna-Greta Jönsson, Gull Andersson and Ewa
Alfvegren for invaluable contributions; and Professor Bertil Alfvegren for invaluable contributions; and Professor Bertil
Diamant for the blood lactate analysis. This work was supported by grants from Swedish Society of Cardiology, Foundation. 
1 Franciosa JA, Park M, Levine TB. Lack of correlation between exercise capacity and indexes of resting left ventricular performance in heart failure. Am $₹$ Cardiol 1981; 47:33-9.

2 Fink LI, Wilson JR, Ferraro N. Exercise ventilation and pulmonary artery wedge pressure in chronic stable congestive hert failure Am 7 ardiol 1986;57:249-53.

3 Lipkin DP, Poole-Wilson PA. Symptoms limiting exercise capacity in chronic heart failure. $\mathrm{Br} \mathrm{Med} \mathcal{F} 1986 ; 292$ $653-55$

4 Wilson JR, Fink LI, Maris J, et al. Evaluation of energy metabolism in skeletal muscle of patients with heart failure with gated phosphorus-31 nuclear magnetic resonance. Circulation 1985;71.57-62.

5 Massie B, Conway M, Yonge $\mathrm{R}$, et al. ${ }^{31} \mathrm{P}$ nuclear magnetic resonance evidence of abnormal skeletal muscle metabolism in patients with congestive heart failure. $A m \mathcal{F}$ Cardio 1987;60:309-15.

6 Mancini DM, Ferraro N, Tuchler M, Chance B, Wilson JR. Detection of abnormal calf muscle metabolism in patients with heart failure using phosphorus-31 nuclear magnetic resonance. Am F Cardiol 1988;62:1234-40.

7 Sullivan MJ, Green HJ, Cobb FR. Altered skeletal muscle metabolic response to exercise in chronic heart failure. Relation to skeletal muscle aerobic enzyme activity. Circulation 1991;84:1597-607.

8 Näveri $H$, Leinonen $H$, Härkönen $M$. Is skeletal muscle creatine depletion the limiting factor of exercise performance in congestive heart failure? Eur Heart $\mathcal{f}$ 1992;13 (abstr suppl): 434

$9 \mathrm{Katz}$ A, Sahlin K. Role of oxygen in regulation of glycolysis and lactate production in human skeletal muscle. Exerc and lactate production in hum
Sport Sci Rev 1990;18:1-28.

10 Francis GS. Neurohumoral mechanisms involved in congestive heart failure. Am $f$ Cardiol 1985;55:15A-21A

11 Eriksson BO, Hanson E. Muscle metabolism during exercise in men operated upon for coarctation of the aorta in childhood. Scand $₹$ Clin Lab Invest 1981;41:135-41.

12 Borg G. Perceived exertion as an indicator of somatic stress. Scand $\mathcal{f}$ Rehab Med 1970;2:92-8.

13 Wasserman K, Whipp BJ, Koyal SN, Beaver WL. Anaerobic threshold and respiratory gas exchange during exercise. $f$ Appl Physiol 1973;35:236-43.

14 Simonton CA, Higginbotham MB, Cobb FR. The ventilatory threshold: quantitative analysis of reproducibility and relation to arterial lactate concentration in normal subjects and patients with chronic congestive heart failure. $A m \mathcal{F}$ Cardiol 1988;62:100-7.

15 Lowry $\mathrm{OH}$, Passoneau JV. A flexible system of enzyme analysis. New York: Academic Press, 1972;195-6.

16 Walsh P, Wang M, Gitterman M. A simplified radioim munoassay for plasma aldosterone. Ann Clin Lab Sci 1981, 11:138-45.

17 Nussberger J, Beckerhoff R, Vetter W, Armbruster $H$ Siegenthaler W. Simplified radioimmunoassay for plasma angiotensin II. In: Radio-immunoassay and related procedures in medicine (vol 1). Vienna: International Atomic dures in medicine (vol

18 Tasseron S, Fiolet J, Willebrands A. Evaluation of a radioenzymatic kit for determination of plasma catecholamines. zymatic kit for determina

19 Karlsson J. Lactate and phosphagen concentrations in working muscle of man. Acta physiol scand 1971;supplementum

20 Chi MM-Y, Hintz CS, Coyle EF, et al. Effects of detraining on enzymes of energy metabolism in individual muscle fibers. Am $\mathcal{F}$ Physiol 1983;244:C276-87.

21 Bergmeyer H, Bernt E. Methods of enzymatic analysis. (Bergmeyer H.) Deerfield Beach, Florida: Verlag Chemie, Academic Press, 1974:579.

22 Alp PR, Newsholme EA, Zammit VA. Activities of citrate synthase and $\mathrm{NAD}^{+}$-linked and $\mathrm{NADP}^{+}$-linked isocitrate dehydrogenase in muscle from vertebrates and invertebrates. Biochem 7 1976;154:689-700.

23 Lowry CV, Kimmey JS, Felder S, et al. Enzyme patterns in single human muscle fibers. $f$ Biol Chem 1978;253: 8269-77.

24 Maskin C, Forman R, Sonnenblick EH, Frishman WH, LeJemtel TH. Failure of dobutamine to increase exercise capacity despite haemodynamic improvement in severe chronic heart failure. Am $\mathcal{F}$ Cardiol 1983;51:177-82.

25 Wilson JR, Martin JL, Ferraro N. Impaired skeletal muscle nutritive flow during exercise in patients with congestive heart failure: role of cardiac pump dysfunction as determined by the effect of dobutamine. Am $\mathcal{F}$ Cardiol 1984; 53:1308-15.

26 Massie BM, Conway $M$, Yonge $R$, et al. Skeletal muscle metabolism in patients with congestive heart failure. Relation to clinical severity and blood flow. Circulation 1987;76:1009-19.

27 Mancini DM, Coyle E, Coggan A, et al. Contribution of intrinsic skeletal muscle changes to 31P NMR skeletal muscle metabolic abnormalities in patients with chronic heart failure. Circulation 1989;80:1338-46.

28 Green HJ, Sutton J, Young P, Cymerman A, Houston CS. Operation Everest II: muscle energetics during maxima exhaustive exercise. $\mathcal{f}$ Appl Physiol 1989;66:142-50.

29 Eiken O, Bjurstedt H. Dynamic exercise in man as influenced by experimental restriction of blood flow in the working muscles. Acta Physiol Scand 1987;131: 339-45.

30 Wilson JR, Mancini DM, Ferraro N, Egler J. Effect of dichloroacetate on the exercise performance of patients with heart failure. $₹$ Am Coll Cardiol 1988;12:1464-9.

31 Minotti JR, Pillay P, Chang L, Wells L, Massie BM. Neurophysiological assessment of skeletal muscle fatigue in patients with congestive heart failure. Circulation 1992; in patients

32 Volterrani M, Clark AL, Ludman PF, et al. Predictors of exercise capacity in chronic heart failure. Eur Heart $\mathcal{f}$ 1994;15:801-9.

33 Drexler H, Riede U, Münzel T, König H, Funke E, Just H. Alterations of skeletal muscle in chronic heart failure. Circulation 1992;85:1751-9.

34 Sullivan MJ, Green HJ, Cobb FR. Skeletal muscle biochemistry and histology in ambulatory patients with long-term heart failure. Circulation 1990;81:518-27.

35 Pagliassotti MJ, Donovan CM. Influence of cell heterogeneity on skeletal muscle lactate kinetics. Am F Physiol 1990; 258:E625-34.

36 Hambrecht R, Niebauer J, Fiehn E, et al. Physical training in patients with stable chronic heart failure: effects on cardiorespiratory fitness and ultrastructural abnormalities of leg muscles. 7 Am Coll Cardiol 1995;25:1239-49.

37 Anker SD, Volterrani M, Chua TP, Swan JW, Poole-Wilson PA, Coats AJS. Peak blood flow as a predictor of exercise capacity in cardiac cachexia. Eur Heart $\mathcal{F} 1995 ; 16$ (abstr suppl):356

38 Juhlin-Dannfelt AC, Terblanche SE, Fell RD, Young JC Holloszy JO. Effects of beta adrenergic receptor blockade on glycogenolysis during exercise. $\mathcal{F}$ Appl Physiol 1982; 53:549-54.

39 Kaiser P, Tesch PA, Thorsson A, Karlsson J, Kaijser L Skeletal muscle glycolysis during submaximal exercise following acute $\beta$-adrenergic blockade in man. Acta Physio Scand 1985;123:285-91.

40 Broqvist M, Dahlström U, Karlsson E, Larsson J. Muscle water content and electrolytes in severe chronic congestive heart failure before and after treatment with enalapril. Eur Heart $\mathcal{f} 1992 ; 13: 243-50$.

41 Dyckner T, Wester PO. Plasma and skeletal muscle electrolytes in patients on long-term diuretic therapy for arterial hypertension and/or congestive heart failure. Acta Med Scand 1987;222:231-6. 